Original Research Article

\title{
A study of clinical information of various package inserts: an approach to encourage adverse drug reaction reporting and emphasis on black box warning
}

\author{
Ervilla Dass*
}

Department of Pharmacology, Smt. Bhikhiben Kanjibhai Shah Medical Institute \& Research Centre, Sumandeep Vidyapeeth an institution deemed to be University, At. \& PO. Piparia, Waghodia, Vadodara 391760, Gujarat, India

Received: 23 May 2018 Accepted: 29 May 2018

*Correspondence to: Dr. Ervilla Dass, Email: ervilladass@gmail.com

Copyright: (C) the author(s), publisher and licensee Medip Academy. This is an openaccess article distributed under the terms of the Creative Commons Attribution NonCommercial License, which permits unrestricted noncommercial use, distribution, and reproduction in any medium, provided the original work is properly cited.

\begin{abstract}
Background: The package insert (PI) is important for providing accurate and reliable product information which is essential for the safe and effective use of medications.

Methods: A total number of 115 PIs from pharmacological drug class such as antibiotics, drugs acting on central nervous system and drugs acting on endocrine system were collected from pharmacy store. Contents and presentation of the PIs was critically evaluated by comparing the information as listed in the Drugs and Cosmetics Rules, 1945.

Results: The results were expressed under headings as listed in the Drugs and Cosmetics Rules, 1945. The information in the package inserts was inadequate in many aspects; for example, adverse drug reactions were not mentioned completely, information for special population and guidelines for use of the drugs also was lacking. Moreover, black box warning was seen only in few PI. For PI of antibiotics; legibility $80 \%$, use in special populations $76.66 \%$, undesirable effects $46.66 \%$. For PI of CNS of legibility $60 \%$, use in special populations $73.33 \%$, undesirable effects $70 \%$. For PI of endocrine system of legibility $70 \%$, use in special populations $70 \%$, undesirable effects $36.66 \%$.

Conclusions: The results reveal that, information relevant to the safe and effective use of medication was not mentioned in the analyzed package inserts. It is, therefore, recommended to update the existing package inserts based on criteria mentioned in the Schedule D of Drug and Cosmetic Act, 1945.
\end{abstract}

Keywords: Package insert, Prescription drug labeling, Drugs and cosmetic rule

\section{INTRODUCTION}

The term "Package Insert" describes all forms of product information (formally prescribing information in the United States; in Europe, Patient information leaflet for human medicines or Package Leaflet for veterinary medicines), is a printed leaflet that contains information based on regulatory guidelines for the safe and effective use of a drug. Inserts and documentation are also used in a variety of other non-pharmaceutical products and packages for either providing information to the physician or for drug promotion. ${ }^{1}$ Promotion can be broadly defined using the WHO definition: "all informational and persuasive activities by manufacturers, the effect of which is to induce the prescription, supply, purchase and/or use of medicinal drugs." 2 The safe use of all medicines depends on users reading the package insert carefully and accurately and being able to assimilate and act on the information presented, it must be clear and concise and must bear all necessary information regarding the safe use of a product. Its content should not be promotional, false, or misleading. ${ }^{3}$ 
This drug product information commences early during the developmental phase of a pharmaceutical product with careful scrutiny of available information. In India, the concept of package insert is governed by the 'Drugs and Cosmetics Act (1940) and Rules (1945). The section 6 Labelling and packaging information of drugs, of Schedule D (II) of the rules lists the headings based on which package insert information should be provided. The 'Section 6.2' mandates that the information must be in 'English' and should provides information regarding the specific requirements; which should include information related to the immediate importance to the clinical use of the drug, such as, therapeutic indications, posology and method of administration, contraindications, special warnings and special precautions of use if any, interaction with medicament of other forms of interaction, pregnancy and lactation if contraindicated, effects on ability to drive and use machines if contraindicated, undesirable effects/side effects, and antidote for overdosage. The 'Section 6.3' mandates pharmaceutical information on list of excipients, incompabilities and information regarding shelf life. ${ }^{4}$

In India, many times the healthcare professionals depends on non-commercial source of drug information such as peer-viewed medical journals, standard textbooks, compendiums, gov websites and also on commercial sources of drug information such as promotional literatures for information on drugs; and also likely to depend on product information provided by pharmaceutical companies. However, product information provided by pharmaceutical or marketing companies in India is inadequate and not in accordance with the WHO recommendations. 5,6 Package inserts is an important source of information for physicians regarding the safety and proper administration of a drug. However, recent studies have found that inserts are missing key information regarding a drug's safety and efficacy. ${ }^{7}$

A black box warning can be placed on the medication's bottle or on a printed insert inside the box. Black Box Warnings are issued by the Food and Drug Administration (FDA) to alert medical professionals of potentially serious adverse reactions a drug has demonstrated. The term "Black Box" refers to the fact that at the beginning of the package insert (PI) of the drug there is literally a black box encircling the written warning to capture the reader's attention. The FDA recently began a concerted effort to include more black box warnings on more products to increase public safety. Drugs may carry black box warnings for many reasons and the attached table contains specific examples of them pertinent to the geriatric population. The FDA issues a black box warning to a drug's PI when "there is an adverse reaction so serious in proportion to the potential benefit from the drug that it is essential that it (the black box warning) be considered in assessing the risks and benefits of using the drug." FDA continually monitors drugs after they have been approved to market for safety issues and will often issue a black box warning in response to post marketing surveillance observations where a significant safety issue has emerged. One of the more talked about black box warning drugs in Long-Term Care is the one pertaining to the antipsychotic class of medications. This was issued to let medical practitioners know that when used inappropriately with a resident with dementia, the drug is being used off label, and the patient runs an increased risk of death. The legal ramifications of prescribing black box warning drugs draw scrutiny from practitioners, because using a black box medication in spite of a contraindication can be considered off label use. For these reasons, prescribers, pharmacists, nursing facilities and most importantly patients benefit from being cognizant of FDA black box warnings. ${ }^{8}$

The aim of this present research study was to examine and evaluate the content and presentation of Package Inserts on different brands of generic drugs from various pharmacological drug class such as antibiotics, Drugs Acting On Central Nervous System and endocrine system. Although the results of previous studies on package inserts showed that there was an overall improvement in the percentage of inserts containing relevant information, a need to further refine the contents of the package inserts is essential with also an emphasis on mentioning adverse drug reactions/side effects and whether package inserts are in conformance with the Indian regulatory guidelines. ${ }^{9}$

\section{METHODS}

Package inserts or leaflets that were supplied along with allopathic drug products marketed by various pharmaceutical/marketing companies in India were collected on request from two pharmacy stores located in Vadodara, India, during a period of two years. The PI were further scrutinised and Patient Information Leaflets were identified from the patient-directed language used in the leaflets and duplicates (same drug, formulation, and company) were excluded from the study.

A total number of 90 package inserts were included in the study which were of different brands of generic identical drugs from various pharmacological drug class such as antibiotics, drugs acting on Central Nervous System and endocrine system. The package inserts which were included in the study were evaluated for analysis for the content of clinically important information in various sections as mentioned in Table 1, which was further compared with the Standard Information Sources (Pharmacopoeias, Martindale - The complete drug reference, $36^{\text {th }}$ Edition, British National Formulary, Essentials of medical pharmacology by K. D. Tripathi $6^{\text {th }}$ edition, Jaypee Publication, USP DI, WHO recommendations, Drugs and cosmetics rule, 1945 India, Food and Drug Administration, etc.). The package inserts were evaluated for the clinical information, which were analyzed based on the headings mentioned in 'Section 6.2' of Schedule D of Drugs and Cosmetics Rules, $1945 .{ }^{4}$ The package insert was checked for the presence or absence of relevant information to the concerned heading and were scored as zero accordingly as zero for absence and one for 
presence of relevant information. The total scores for each heading were calculated by totalling the scores from individual package inserts. The total scores were expressed as absolute numbers and percentages as mentioned in Table 2 for the three pharmacological drug classes. Information related to black box warning and pharmacological and pharmaceutical properties of the drugs were also analyzed.

\section{RESULTS}

Statistical Analysis: The results were expressed as absolute numbers and percentages.

A total number of 115 PIs from pharmacological drug class such as antibiotics, drugs acting on central nervous system and drugs acting on endocrine system were evaluated. The results were expressed under headings such as, therapeutic indications, contraindications, undesirable effects, etc., as listed in the Drugs and Cosmetics Rules, 1945. The clinical information included in the package insert was analyzed according to the Drugs and Cosmetics Rules, $1945,{ }^{4}$ and various standard guidelines. Quality of information presented was assessed and scores were given for adherence to Indian i.e. Schedule D of Drugs and Cosmetics Rules, 1945, India as mentioned in Table 1.

All the 115 PIs to be evaluated were scrutinized and out of that 15 PI which were related to patient information leaflets were excluded as depicted in Table 1.

Table 1: Total number of package inserts evaluated from various group on different brands.

\begin{tabular}{|lll|}
\hline $\begin{array}{l}\text { Pharmacological } \\
\text { drug class }\end{array}$ & $\begin{array}{l}\text { Number of } \\
\text { package inserts } \\
\text { included }\end{array}$ & $\begin{array}{l}\text { Number of } \\
\text { package inserts } \\
\text { excluded }\end{array}$ \\
\hline Antibiotics & 30 & 04 \\
\hline $\begin{array}{l}\text { Drugs acting on } \\
\text { central nervous } \\
\text { system }\end{array}$ & 30 & 03 \\
\hline $\begin{array}{l}\text { Drugs acting on } \\
\text { endocrine system }\end{array}$ & 30 & 08 \\
\hline
\end{tabular}

Out of total 30 PIs from the pharmacological drug class Antibiotics, Legibility was observed in $80 \%$, which shows better compliance to patients. Information regarding the use of medication in special populations such as pregnant women, lactating women, paediatric patients, geriatric patients and also related to hepatic insufficiency and renal insufficiency was not clearly specified 07 PI out of 30 (76.66\%). Information such as International NonProprietary Name of active ingredient, Content of active ingredient per dosage form, Therapeutic Indications, Posology and method of administration, and information on packaging and shelf and storage was completely mentioned in the 30 PI (100\%).

Table 2: Evaluation of labelling and packaging information of drugs of pharmacological drug class - antibiotics.

\begin{tabular}{|llll|}
\hline Labelling and packaging information of drugs & Antibiotics (30 PI) \\
\hline Legibility & Present & Absent & Percentage score of PIs \\
\hline International Non-Proprietary Name of active ingredient & 24 & 06 & 80 \\
\hline Content of active ingredient per dosage form & 30 & 0 & 100 \\
\hline Generic names of other ingredients & 30 & 0 & 100 \\
\hline Therapeutic Indications & 30 & 0 & 100 \\
\hline Posology and method of administration & 30 & 0 & 100 \\
\hline $\begin{array}{l}\text { Use in special populations } \\
\text { (such as pregnant women, lactating women, paediatric patients, } \\
\text { geriatric patients etc.) }\end{array}$ & 30 & 0 & 100 \\
\hline Interaction with other medicaments and other forms of interaction & 23 & 07 & 76.66 \\
\hline Contraindications & 30 & 0 & 100 \\
\hline Effects of ability to drive and use machines, if contra-indicated. & 22 & 08 & 73.33 \\
\hline Undesirable effects/side effects. & NA & NA & NA \\
\hline Antidote for overdosing. & 14 & 16 & 46.66 \\
\hline Pharmacokinetic properties & NA & NA & NA \\
\hline Incompatibility & 26 & 04 & 86.66 \\
\hline Shelf life & 30 & 0 & 100 \\
\hline Packaging information & 30 & 0 & 100 \\
\hline Storage instructions & 30 & 0 & 100 \\
\hline Instructions for use and handling & 30 & 0 & 100 \\
\hline Date on which information was last updated & 30 & 0 & 100 \\
\hline Name and address of manufacturer/distributor & 12 & 18 & 40 \\
\hline Provision of full information on request should be highlighted & 30 & 0 & 100 \\
\hline References & 30 & 0 & 100 \\
\hline
\end{tabular}


While it was observed that in $46.66 \%$ of PI mentioned adverse drug reactions (ADRs) which show lack of information regarding safety of patients. It is important that clinicians should be aware about the drugs they prescribe and should ensure that all necessary steps are taken to reduce and minimize the ADRs. They should be vigilant in detecting unusual, unlisted ADRs, and should report to authorities and thus contribute to patient safety and advice patients or their caretakers also to notify the ADR if any. Other contents such as Pharmacokinetic properties was observed in PIs were $86.66 \%$.

Many of the pharmaceutical companies lack in updating the PI, which was observed in 40\%; and citation of references for relevant evidence-based information was also lacking in majority of the PI $(40 \%)$ as shown in Table 2.

Out of total 30 PIs from the pharmacological drug class Drugs Acting on Central Nervous System, Legibility was observed in $60 \%$. Special populations such as pregnant women, lactating women, paediatric patients, geriatric patients and also related to hepatic insufficiency and renal insufficiency was $73.33 \%$. Information such as International Non-Proprietary Name of active ingredient, Content of active ingredient per dosage form, Therapeutic Indications, Posology and method of administration, Contraindications and information on packaging and shelf and storage was completely mentioned in all $30 \mathrm{PI}$.

Adverse drug reactions (ADRs) or side effects were observed in $70 \%$ PIs; other contents such as Pharmacokinetic properties was observed in PIs were $56.66 \%$, many of the pharmaceutical companies lack in updating the PI, which was observed in $30 \%$; and citation of references for relevant evidence-based information was also lacking in majority of the PI $(46.66 \%)$ as shown in Table 3 .

Table 3: Evaluation of labelling and packaging information of drugs of pharmacological drug class - drugs acting on central nervous system.

\begin{tabular}{|llll|}
\hline Labelling and packaging information of drugs & \multicolumn{3}{l}{ Drugs acting on central nervous system (30 PI) } \\
\hline Legibility & Present & Absent & Percentage score of PIs \\
\hline International Non-Proprietary Name of active ingredient & 18 & 12 & $\mathbf{6 0}$ \\
\hline Content of active ingredient per dosage form & 30 & 0 & 100 \\
\hline Generic names of other ingredients & 30 & 0 & 100 \\
\hline Therapeutic Indications & 30 & 0 & 100 \\
\hline Posology and method of administration & 30 & 0 & 100 \\
\hline $\begin{array}{l}\text { Use in special populations } \\
\text { (such as pregnant women, lactating women, paediatric patients, } \\
\text { geriatric patients etc.) }\end{array}$ & 30 & 0 & 100 \\
\hline Interaction with other medicaments and other forms of interaction & 22 & 08 & 73.33 \\
\hline Contraindications & 30 & 0 & 100 \\
\hline Effects of ability to drive and use machines, if contra-indicated. & 30 & 0 & 100 \\
\hline Undesirable effects/side effects. & NA & NA & NA \\
\hline Antidote for overdosing. & 21 & 09 & 70 \\
\hline Pharmacokinetic properties & NA & NA & NA \\
\hline Incompatibility & 17 & 13 & 56.66 \\
\hline Shelf life & 30 & 0 & 100 \\
\hline Packaging information & 30 & 0 & 100 \\
\hline Storage instructions & 30 & 0 & 100 \\
\hline Instructions for use and handling & 30 & 0 & 100 \\
\hline Date on which information was last updated & 30 & 0 & 100 \\
\hline Name and address of manufacturer/distributor & 09 & 21 & 30 \\
\hline Provision of full information on request should be highlighted & 30 & 0 & 100 \\
\hline References & 30 & 0 & 100 \\
\hline & 14 & 16 & 46.66 \\
\hline
\end{tabular}

Out of total 30 PIs from the pharmacological drug class Drugs Acting on endocrine system, legibility and information for special populations was observed in $70 \%$ of PIs. Observations made on the information such as International Non-Proprietary Name of active ingredient,
Content of active ingredient per dosage form, Therapeutic Indications, Posology and method of administration, Contraindications and information on packaging and shelf and storage was $100 \%$. 
Adverse drug reactions (ADRs) or side effects were observed in only $36.66 \%$ PIs; mainly described as summary or in few words such as drug is well tolerated and ADRs related to the drug were mild, transient, and rare, where the serious ADRs associated with the products were highlighted in few PIs. Observation on other contents such as Pharmacokinetic properties was $70 \%$, many of the pharmaceutical companies lack in updating the PI, which was observed in $46.66 \%$; and citation of references for relevant evidence-based information was also lacking in majority of the PI (30\%) as shown in Table 4.

In general, overall presentation of information in majority of package insert was not uniform and information were not mentioned in clear separate headings, though included, hence making it difficult to access information easily due to lack of a common layout and headings. Indications for use and contraindications were mentioned most consistently in the package inserts studied.

Table 4: Evaluation of labelling and packaging information of drugs of pharmacological drug class - drugs acting on endocrine system.

\begin{tabular}{|c|c|c|c|}
\hline \multirow{2}{*}{ Labelling and packaging information of drugs } & \multicolumn{3}{|c|}{ Drugs Acting on endocrine system (30 PI) } \\
\hline & Present & Absent & Percentage score of PIs \\
\hline Legibility & 21 & 09 & 70 \\
\hline International Non-Proprietary Name of active ingredient & 30 & 0 & 100 \\
\hline Content of active ingredient per dosage form & 30 & 0 & 100 \\
\hline Generic names of other ingredients & 30 & 0 & 100 \\
\hline Therapeutic Indications & 30 & 0 & 100 \\
\hline Posology and method of administration & 30 & 0 & 100 \\
\hline $\begin{array}{l}\text { Use in special populations } \\
\text { (such as pregnant women, lactating women, paediatric patients, } \\
\text { geriatric patients etc.) }\end{array}$ & 21 & 09 & 70 \\
\hline Interaction with other medicaments and other forms of interaction & 30 & 0 & 100 \\
\hline Contraindications & 30 & 0 & 100 \\
\hline Effects of ability to drive and use machines, if contra-indicated. & NA & NA & NA \\
\hline Undesirable effects/side effects. & 11 & 19 & 36.66 \\
\hline Antidote for overdosing. & NA & NA & NA \\
\hline Pharmacokinetic properties & 21 & 09 & 70 \\
\hline Incompatibility & 30 & 0 & 100 \\
\hline Shelf life & 30 & 0 & 100 \\
\hline Packaging information & 30 & 0 & 100 \\
\hline Storage instructions & 30 & 0 & 100 \\
\hline Instructions for use and handling & 30 & 0 & 100 \\
\hline Date on which information was last updated & 14 & 16 & 46.66 \\
\hline Name and address of manufacturer/distributor & 30 & 0 & 100 \\
\hline Provision of full information on request should be highlighted & 30 & 0 & 100 \\
\hline References & 09 & 21 & 30 \\
\hline
\end{tabular}

\section{DISCUSSION}

The Package Inserts is the 'Manual' for the safe and effective use of a drug. It also serves as source of drug information for patients taking over-the-counter as well as prescription medications. The present study evaluated the information available in drug package inserts of India. Important pharmacokinetic and pharmacodynamic properties of a drug product should appear in the Package Inserts under specific sections, as required in Drugs and Cosmetics Rules, $1945 .{ }^{4}$ The present project was designed to assess the availability of information on Package Inserts and Prescription Drug Labelling to doctors. However, the volume of information included in the Package Inserts differed for different brands, and furthermore, the same drug may be registered for different indications.

Extensive scientific investigation of drugs in man and introduction of numerous new drugs over the past few decades is gradually transforming the practice of medicine from "experience based" wherein clinical decisions are based on the experience (or rather impression) of the physician to "evidence based" wherein the same are guided by scientifically credible evidence from welldesigned clinical studies. Today's physician has to be skilled in searching and evaluating the literature on 
efficacy, safety and appropriateness of a particular therapeutic measure (drug). ${ }^{10}$ Package inserts is an essential feature of drug packaging. These inserts are present in most of the medicinal and pharmaceutical products as a piece of paper with information pertaining to that particular product. Often unread they have potential educational and legal implications. ${ }^{11}$

\section{CONCLUSION}

Thus, the results of the study indicate that information on safe and appropriate use of medications was not uniformly provided in the PI marketed in India. It is an important responsibility of the prescriber to be completely familiar with the labelling details before use of a medication. This evaluation shows that prescribing physicians need to be careful about situations in which they utilize medications for indications and at dosages outside of what is described in the package insert. A more meticulous approach in preparation of PI and drug label to include approved, essential, accurate, evidence-based and updated prescribing information is needed.

\section{ACKNOWLEDGEMENTS}

Author is grateful to Smt. Bhikhiben Kanjibhai Shah Medical Institute and Research Centre, Sumandeep Vidyapeeth an Institution deemed to be University, Piparia, Vadodara, for permitting to conduct the study.

Funding: No funding sources Conflict of interest: None declared

Ethical approval: The study was approved by the Institutional Ethics Committee of Sumandeep Vidyapeeth (SVIEC), Sumandeep Vidyapeeth Deemed to be University, Piparia, India

\section{REFERENCES}

1. Ved JK. Package Inserts in India: Need for a Revision. Int J of Pha Sci and Rese. 2010;1(11):454-56.

2. World Health Organization and Health Action International, 2005. Drug promotion, what we know, what we have yet to learn. Reviews of materials in the WHO/HAIdatabase on drug promotion. Available at: http://apps.who.int/medicinedocs/pdf/s8109e/s8109e. pdf . Accessed 14 October, 2015.

3. Ramdas D, Chakraborty A, Swaroop HS, Syed F, Kumar PV, Srinivas BN. A Study of Package Inserts in Southern India. J of Cli and Diag Resea. 2013 Nov;7(11):2475-7.

4. Govt. of India, Ministry of Health and Family Welfare. Drug and Cosmetics Rules, 1945. Available at: http://cdsco.nic.in/html/DrugsandCosmeticAct.pdf. Accessed 11 Nov, 2011.

5. Prosser H, Almond S, Walley T. Influences on GPs' decision to prescribe new drugs-the importance of who says what. Fam Pract. 2003;20:61-8.

6. Rajan MS, Sreedhar, Khan SA, Thiyagu R, Rao PG. Information seeking behaviour of clinicians in a semi urban town in southern India. J Clin Diag Res. 2008;2:1069-73.

7. Zaghi D, Maibach HI. Survey of safety and efficacy information in drug inserts for topical prescription medications. Am J Clin Dermatol. 2007;8(1):43-6.

8. An Introduction to the Improved FDA Prescription Drug Labeling. Available at: https://www.fda.gov/downloads/training/forhealthpro fessionals/ucm090796.pdf. Accessed 11 Nov, 2011.

9. Lal A, Sethi A. Drug package inserts in India. Ann Pharmacother. 1996;30:1041.

10. Essentials of medical pharmacology. Chapter 5: Aspects of pharmacotherapy; clinical pharmacology and drug development, page $71 ; 6^{\text {th }}$ Edition, Jaypee Publication, New Delhi; 2008.

11. Bansal V, Dhamija P, Medhi B, Pandhi P. Package Inserts-do they have any role? JK- Practitioner. 2006;13(3):152-4.

Cite this article as: Dass E. A study of clinical information of various package inserts: an approach to encourage adverse drug reaction reporting and emphasis on black box warning. Int J Basic Clin Pharmacol 2018;7:1232-7. 